\title{
BMJ Open The future of population registers: linking routine health datasets to assess a population's current glycaemic status for quality improvement
}

\author{
Wing Cheuk Chan, ${ }^{1}$ Gary Jackson, ${ }^{2}$ Craig Shawe Wright, ${ }^{3}$ Brandon Orr-Walker, ${ }^{4}$ \\ Paul L Drury, ${ }^{5}$ D Ross Boswell, ${ }^{6}$ Mildred Ai Wei Lee, ${ }^{1}$ Dean Papa, ${ }^{1}$ Rod Jackson ${ }^{7}$
}

To cite: Chan WC, Jackson G, Wright CS, et al. The future of population registers: linking routine health datasets to assess a population's current glycaemic status for quality improvement. BMJ Open 2014:4:e003975.

doi:10.1136/bmjopen-2013003975

- Prepublication history for this paper is available online. To view these files please visit the journal online (http://dx.doi.org/10.1136/ bmjopen-2013-003975)

Received 9 September 2013 Revised 18 March 2014 Accepted 19 March 2014

CrossMark

For numbered affiliations see end of article.

Correspondence to Dr W C Chan; wingcheuk.chan@cmdhb.org.nz

\section{ABSTRACT}

Objectives: To determine the diabetes screening levels and known glycaemic status of all individuals by age, gender and ethnicity within a defined geographic location in a timely and consistent way to potentially facilitate systematic disease prevention and management.

Design: Retrospective observational study.

Setting: Auckland region of New Zealand.

Participants: 1475347 people who had utilised publicly funded health service in New Zealand and domicile in the Auckland region of New Zealand in 2010. The health service utilisation population was individually linked to a comprehensive regional laboratory repository dating back to 2004.

Outcome measures: The two outcomes measures were glycaemia-related blood testing coverage (glycated haemoglobin (HbA1c), fasting and random glucose and glucose tolerance tests), and the proportions and number of people with known dysglycaemia in 2010 using modified American Diabetes Association (ADA) and WHO criteria.

Results: Within the health service utilisation population, 792560 people had had at least one glucose or $\mathrm{HbA} 1 \mathrm{c}$ blood test in the previous 5.5 years. Overall, $81 \%$ of males ( $n=198086)$ and $87 \%$ of females $(n=128982)$ in the recommended age groups for diabetes screening had a blood test to assess their glycaemic status. The estimated age-standardised prevalence of dysglycaemia was highest in people of Pacific Island ethnicity at $11.4 \%(95 \% \mathrm{Cl} 11.2 \%$ to $11.5 \%$ ) for males and $11.6 \%$ (11.4\% to $11.8 \%$ ) for females, followed closely by people of Indian ethnicity at $10.8 \%(10.6 \%$ to $11.1 \%)$ and $9.3 \%(9.1 \%$ to $9.6 \%)$, respectively. Among the indigenous Maori population, the prevalence was $8.2 \%(7.9 \%$ to $8.4 \%)$ and $7 \%(6.8 \%$ to $7.2 \%)$, while for 'Others' (mainly Europeans) it was $3 \%$ (3\% to $3.1 \%$ ) and $2.2 \%(2.1 \%$ to $2.2 \%$ ), respectively.

Conclusions: We have demonstrated that the data linkage between a laboratory repository and national administrative datasets has the potential to provide a systematic and consistent individual level clinical information that is relevant to medical auditing for a large geographically defined population.

\section{Strengths and limitations of the study}

- This study applied a method that aims to address the common systematic biases seen in many population diabetes prevalence studies such as incomplete coverage of the population at risk, inconsistency in the definition of diabetes, selection and patient recall bias, measurement errors and misdiagnosis.

- The definition of dysglycaemia included people with confirmed diabetes as well as people who required follow-up tests to confirm the formal diagnosis of diabetes.

- The study did not have information related to patients' symptoms or the ability to differentiate types 1 and 2 diabetes.

\section{INTRODUCTION}

The number of people with diabetes increased globally by almost 200 million from 1980 to $2008 .^{1}$ In the context of a potential 'diabetes epidemic', an accurate and timely measure of diabetes prevalence is critical to inform policy making, resource allocation and planning and implementation of interventions to improve the quality of care for people with diabetes. Moreover, a consistent and systematic way to identify individuals for diabetes screening, follow-up and management is necessary to ensure that people with diabetes receive the most appropriate care. Indeed, randomised controlled trials have demonstrated that the use of electronic patient registers, patient reminders or clinician reminders is associated with quality improvement in diabetes management. ${ }^{2}$ However, the limitations of existing methods to identify populations with diabetes include incomplete coverage of the population at risk, inconsistency in the definition of diabetes, selection and patient recall bias, measurement errors, misdiagnosis, lack of 
precision by age, gender or ethnicity and inadequate adjustments for migrations or deaths. ${ }^{1}{ }^{3-6}$

Auckland (New Zealand) has an ethnically diverse population of over 1.4 million people. The aim of this study is to use laboratory results (between 1 January 2004 and 30 June 2010) from a regional laboratory repository to estimate glycaemia test coverage and glycaemic status in a geographical defined population in 2010. This study proposes a set of methods that utilises 'real-world' routinely collected data in a practical manner that has the potential to provide critical and succinct information for the responsible clinicians that is robust enough at the individual level for quality improvement as well as estimates at the aggregated population level.

\section{METHODS}

\section{Date sources}

TestSafe is a comprehensive data repository containing all the community and hospital laboratory test results requested in the Auckland metropolitan region in New Zealand since July 2006. Individual patient laboratory tests can be requested by general practitioners, privately or publicly funded specialists, resident medical staff or other allied health workers. Prior to July 2006, only hospital test results and community results that were sent to secondary care clinicians were recorded in the data repository. Fasting glucose, random glucose, $2 \mathrm{~h}$ postglucose load values (standard $75 \mathrm{~g}$ oral glucose tolerance test) and glycated haemoglobin (HbA1c) results from 1 January 2004 to 30 June 2010 were sourced from the TestSafe repository. The following routine administrative datasets were sourced from the Analytical Services team within the National Health Board of the Ministry of Health $(\mathrm{MOH})$ (formerly known as the New Zealand Health Information service (NZHIS)):

- National Minimum Dataset (hospital events; NMDS)

- National Non-admitted Patient Collection (outpatients and community visits; NNPAC)

- Pharmaceutical Collection (PHARMHOUSE)

- Laboratory Claims Collection (note: does not include test results)

- Primary Health Organisation (PHO) Enrolment Collection

- General Medical Subsidy Data Mart

- National Mortality Collection

- National Immunisation Register.

\section{Data linkage}

Virtually all health service users in New Zealand are assigned a unique identifier called the National Health Index (NHI). The NHI coverage is estimated to be $98 \%$ of the New Zealand population. ${ }^{7}$ Additional information regarding the purpose and the use of $\mathrm{NHI}$ is available on the New Zealand MOH website. ${ }^{8}$ All NHIs used in this study were encrypted to protect the privacy and confidentiality of health information. Record linkage of various data sources was carried out using encrypted NHIs.
Inclusion criteria of the study

The linkage of the available administrative datasets by unique encrypted NHI was undertaken to derive the 'health service utilisation (HSU) population.' This was defined as New Zealand residents who resided within the boundaries of the three District Health Boards located in the Auckland metropolitan region and received any of the publicly-funded health services in New Zealand between 1 July 2009 and 30 June 2010, namely:

- Currently enrolled in a PHO or people who had a health service contact with a PHO;

- Publicly funded inpatient and outpatient secondary care events (including mental health and emergency department contact);

- Any community pharmaceutical dispensing;

- Any community laboratory test (including outside the Auckland metropolitan region) including the ones requested by privately funded health professionals;

- Any immunisation received as indicated by the national immunisation register.

Deceased individuals were excluded from the HSU population using the National Mortality Collection. In New Zealand, PHOs supply general practitioner services and are publicly funded, receiving a capitation payment for each enrollee. PHOs are required to provide a defined set of essential services which include appropriate evidence-based screening, risk assessment and the use of recall and reminder systems. ${ }^{9}$

\section{Numerator 1: glycaemic status test coverage}

The glycaemic status test coverage by age and ethnicity was estimated as the proportion of the HSU population who had at least one glucose or HbAlc blood test recorded in TestSafe repository from 1 January 2004 to 30 June 2010. Laboratory tests with missing results or results with $<1 \mathrm{mmol} / \mathrm{L}$ for glucose test, or $<1 \%$ $(<0 \mathrm{mmol} / \mathrm{mol})$ of $\mathrm{HbAlc}$ were excluded.

\section{The glycaemic status test coverage}

The number of people who had at least one diabetes blood test in Auckland metro

$$
\begin{aligned}
& =\frac{\text { from } 1 \text { January } 2004 \text { to } 30 \text { June } 2010}{\text { Correponding number of people }} \\
& \text { in the health service utilisation population }
\end{aligned}
$$

\section{Definition of dysglycaemia}

The definition of diabetes recommended by the American Diabetes Association in 2010 and the WHO consultation in 2011 was modified for this 'real-world' study, ${ }^{10}{ }^{11}$ and termed 'dysglycaemia'. The operational definition of this study was to identify a cohort of people with abnormalities of glucose metabolism, who are at high risk of cardiovascular complications rather than only the people who had a confirmed diagnosis of diabetes. This defined cohort should be followed up by the 
healthcare system for ongoing clinical support and management. The dysglycaemic status was derived directly from the laboratory results recorded in a TestSafe laboratory repository for each person in the HSU population. Duplicated test results with identical laboratory numbers for the same person were removed. A person was defined to have dysglycaemia if they had:

- at least one HbA1c test $\geq 6.5 \%$ (equivalent to $48 \mathrm{mmol} / \mathrm{mol}$ ) or

- at least one 2 hour postglucose load $\geq 11.1 \mathrm{mmol} / \mathrm{L}$ on a glucose tolerance test (GTT)

- two or more tests of random glucose $\geq 11.1 \mathrm{mmol} / \mathrm{L}$ and/or fasting glucose $\geq 7.0 \mathrm{mmol} / \mathrm{L}$ on a different day.

For young children less than 10 years of age in 2010 , hospital requested glucose tests were not examined because high glucose results in hospitals for young children are more likely to relate to artificial nutritional feeds or parenteral nutrition than to diabetes.

\section{Comparison to hospital diagnosis}

People within the HSU population who had a previous hospitalisation with a primary or secondary diagnosis of diabetes from 1 July 1999 to 30 June 2010 in New Zealand were identified by (International Classification of Diseases (ICD) 10 codes Edition 3 E10-E14, and O240-O243). The hospital diagnoses were compared with the laboratory diagnosis of dysglycaemia as defined by this study.

\section{Demographic variables}

The dysglycaemic status for each person within the HSU population was determined by the blood test results. The demographic variables including adjustment for migration and deaths were carried out in an identical way for both the numerator (people who had at least one glucose or HbA1c blood test or people with dysglycaemia) and denominator (HSU population which includes people with dysglycaemia or diabetes). Ethnicity was determined as per ethnicity data protocols published by the New Zealand MOH using the prioritised method. ${ }^{12}$ Age was calculated from date of birth with reference to 1 January 2010.

\section{Age standardisation}

The prevalence proportions were separated into 5-year age groups from $<15$ to $\geq 85$ for direct age standardisation using the WHO World population as the standard ${ }^{13}$; 95\% CIs are presented.

\section{RESULTS}

There were 1475347 people living in the Auckland metropolitan region as defined by the HSU population in June 2010. The estimated population of the three Auckland metropolitan District Health Boards from Statistics New Zealand in June 2010 was $1477600 .{ }^{14}$ A total of 4281599 glucose and HbA1c blood tests were analysed from 792588 people who had at least one glycaemia-related blood test in the study period. There were 1458350 tests performed in laboratories based in hospitals (34\% of the total) and 2823249 tests performed by community laboratories $(66 \%)$. There were 38 people who had a glycaemia-related blood test but did not have a gender recorded, and all had age recorded. The proportions of people receiving at least one glucose or HbAlc blood test by age, gender and ethnicity are shown in tables 1 and 2. The age groups highlighted in yellow are the recommended age ranges for diabetes screening as per New Zealand Cardiovascular Guidelines. ${ }^{15}$

The test coverage varies by age, gender and ethnicity. Overall, $81 \%$ of males $(n=198086)$ and $87 \%$ of females $(n=128983)$ in the recommended age groups for diabetes screening had a glycaemia-related blood test recorded at the regional laboratory repository from 1 January 2004 to 30 June 2010. There were a total of 78828 people with dysglycaemia as defined by this study living in the Auckland metropolitan region in 2010 identified by the laboratory results. Crude prevalence was $5.3 \%$ overall (with $5.7 \%$ males, $5 \%$ females). Pacific and Indian ethnicities had the highest age standardised prevalence in the Auckland metropolitan region. There were 31282 people in the HSU population who had been discharged from hospital in New Zealand with a discharge diagnosis of diabetes between 1 July 2000 and 30 June 2010. Of these people, $91 \%(n=28489)$ also had laboratory results consistent with dysglycaemia as defined by this study.

\section{DISCUSSION}

This study estimated the prevalence of dysglycaemia in a consistent manner within a geographically defined population of over 1.4 million by age, gender and ethnicity based on laboratory results sourced from a comprehensive regional laboratory repository (figures 1 and 2). If the data linkage methodology used in this study were implemented in a live electronic population register, one could potentially identify individuals who were yet to be screened for diabetes and people who would probably benefit from intensive ongoing clinical follow-up and management of the cardiovascular risk factors and complications associated with hyperglycaemia in a consistent, comprehensive and timely way. We have demonstrated that glycaemia-related blood testing coverage is very high in the Auckland metropolitan region, and apparently higher than previously reported in Ontario, Canada in $2005 .{ }^{6}$ In Auckland, more than $85 \%$ of men and $84 \%$ of women over 55 in 2010 have had one or more glucose or HbA1c blood tests since 2004. Females of childbearing age (aged 15-49) were also more likely to have glucose or HbAlc blood tests than their male counterparts for comparable age and ethnic groups. Overall, the blood test coverage for females between 15 and 49 years of age was $7.7 \%$ higher than that for males. 
Table 1 Proportion of males receiving a glycaemia-related blood test in the Auckland metropolitan region in 2010

\begin{tabular}{llllllllr}
\hline Age & Maori (\%) & Pacific (\%) & Indian (\%) & Chinese & $\begin{array}{l}\text { Other } \\
\text { Asian (\%) }\end{array}$ & Others (\%) & $\begin{array}{c}\text { Absolute } \\
\text { Overall (\%) }\end{array}$ & $\begin{array}{l}\text { number tested } \\
\text { numb }\end{array}$ \\
\hline$<15$ & 15.1 & 15.6 & 16.1 & 10.5 & 10.9 & 14.3 & 14.4 & 24465 \\
$15-19$ & 25.9 & 23.9 & 23.7 & 16.9 & 17.1 & 25.5 & 24.2 & 12989 \\
$20-24$ & 41.1 & 38.5 & 36.4 & 26.3 & 28.3 & 38.3 & 37.3 & 18590 \\
$25-29$ & 44.2 & 43.0 & 42.2 & 29.0 & 34.5 & 40.2 & 39.9 & 18811 \\
$30-34$ & 49.9 & 51.2 & 54.5 & 36.5 & 40.0 & 43.4 & 45.8 & 20744 \\
$35-39$ & 58.7 & 60.5 & 66.9 & 49.7 & 51.7 & 51.1 & 54.5 & 28010 \\
$40-44$ & 66.8 & 70.4 & 78.0 & 58.6 & 59.1 & 61.7 & 64.2 & 34175 \\
$45-49$ & 75.1 & 77.4 & 83.5 & 66.8 & 68.1 & 70.9 & 72.5 & 38417 \\
$50-54$ & 82.4 & 84.8 & 87.5 & 76.9 & 76.4 & 79.3 & 80.4 & 36440 \\
$55-59$ & 88.3 & 89.1 & 88.2 & 79.2 & 80.3 & 85.2 & 85.4 & 32353 \\
$60-64$ & 92.5 & 90.9 & 88.9 & 84.4 & 86.3 & 89.3 & 89.2 & 30043 \\
$65-69$ & 94.3 & 92.1 & 87.8 & 84.5 & 88.2 & 92.0 & 91.4 & 22206 \\
$70-74$ & 95.8 & 92.1 & 88.6 & 87.1 & 88.3 & 94.2 & 93.1 & 16649 \\
$75-79$ & 95.1 & 92.2 & 90.1 & 88.3 & 85.7 & 94.9 & 93.9 & 11730 \\
$80-84$ & 96.1 & 90.6 & 89.8 & 87.8 & 84.7 & 96.0 & 95.0 & 8276 \\
$>85$ & 98.3 & 87.6 & 87.0 & 85.0 & 84.7 & 95.9 & 95.1 & 5670 \\
Total & & & & & & & & 359567 \\
\hline
\end{tabular}

Table order reflects the ethnicity priority order; 'Other' includes those of European descent.

Consistent with the New Zealand cardiovascular disease risk management guideline recommendation to screen Maori, Pacific and Indian people 10 years earlier than others, the age-specific blood test coverage was higher in these ethnic groups than in other groups in the age groups between 35 and 45 years for men and between 45 and 55 years for women. ${ }^{15}$ Since $34 \%$ of blood tests were carried out in hospital laboratories, it was likely that a small number of tests were undertaken because of symptoms related to diabetes rather than opportunistic screening for diabetes. Since the rate of hospital admissions increases with advancing age, the relatively high coverage of diabetes testing in the older groups may in part be a result of routine glucose testing for most patients admitted to hospitals.

Consistent with previous reports, the ethnic disparities in prevalence of dysglycaemia were alarming. ${ }^{16}$ This study demonstrated that Pacific and Indian people have the highest age standardised prevalence of dysglycaemia (table 3). Almost one in two Pacific women aged 70-74 had evidence of dysglycaemia (figure 2). These findings highlight the critical need for primary and secondary prevention efforts to reduce ethnic disparities in diabetes-related morbidity and mortality. A previously published estimate of diabetes prevalence for the southern part of the region Counties Manukau District

Table 2 Proportion of females receiving a glycaemia-related blood test in the Auckland metropolitan region in 2010

\begin{tabular}{|c|c|c|c|c|c|c|c|c|}
\hline Age & Maori (\%) & Pacific (\%) & Indian (\%) & Chinese (\%) & $\begin{array}{l}\text { Other } \\
\text { Asian (\%) }\end{array}$ & Others (\%) & Overall (\%) & $\begin{array}{l}\text { Absolute } \\
\text { number tested }\end{array}$ \\
\hline$<15$ & 12.9 & 12.9 & 14.5 & 8.8 & 8.8 & 12.7 & 12.5 & 20123 \\
\hline $15-19$ & 36.6 & 27.4 & 29.4 & 18.1 & 17.7 & 33.4 & 30.6 & 16855 \\
\hline 20-24 & 59.9 & 52.1 & 50.3 & 32.5 & 36.1 & 50.3 & 50.2 & 27144 \\
\hline 25-29 & 65.8 & 64.4 & 61.0 & 40.6 & 47.3 & 52.3 & 54.9 & 31348 \\
\hline 30-34 & 67.4 & 68.4 & 70.7 & 54.4 & 53.3 & 58.5 & 61.5 & 34129 \\
\hline 35-39 & 69.5 & 71.0 & 76.7 & 61.6 & 56.6 & 63.0 & 65.2 & 39085 \\
\hline $40-44$ & 72.2 & 75.2 & 80.1 & 68.1 & 63.3 & 66.9 & 69.2 & 41014 \\
\hline $45-49$ & 79.4 & 81.2 & 85.7 & 76.7 & 68.3 & 71.8 & 74.6 & 42334 \\
\hline $50-54$ & 84.8 & 85.8 & 89.1 & 81.0 & 77.7 & 78.5 & 80.6 & 38528 \\
\hline $55-59$ & 88.6 & 88.8 & 87.8 & 81.4 & 83.5 & 83.2 & 84.3 & 33735 \\
\hline $60-64$ & 92.3 & 91.4 & 88.0 & 85.9 & 86.4 & 86.9 & 87.6 & 30489 \\
\hline $65-69$ & 94.6 & 91.4 & 89.2 & 86.9 & 86.3 & 90.3 & 90.3 & 23404 \\
\hline 70-74 & 95.2 & 93.4 & 89.7 & 87.7 & 87.5 & 92.7 & 92.3 & 18120 \\
\hline 75-79 & 94.8 & 92.3 & 89.0 & 89.1 & 85.8 & 94.6 & 93.7 & 13754 \\
\hline 80-84 & 95.5 & 89.0 & 87.8 & 87.2 & 88.4 & 95.6 & 94.6 & 11095 \\
\hline$>85$ & 97.4 & 90.8 & 87.3 & 88.6 & 80.2 & 96.1 & 95.5 & 11796 \\
\hline Total & & & & & & & & 432953 \\
\hline
\end{tabular}


Figure 1 Age specific prevalence of dysglycaemia in the Auckland metropolitan region in 2010 by ethnicity (males).

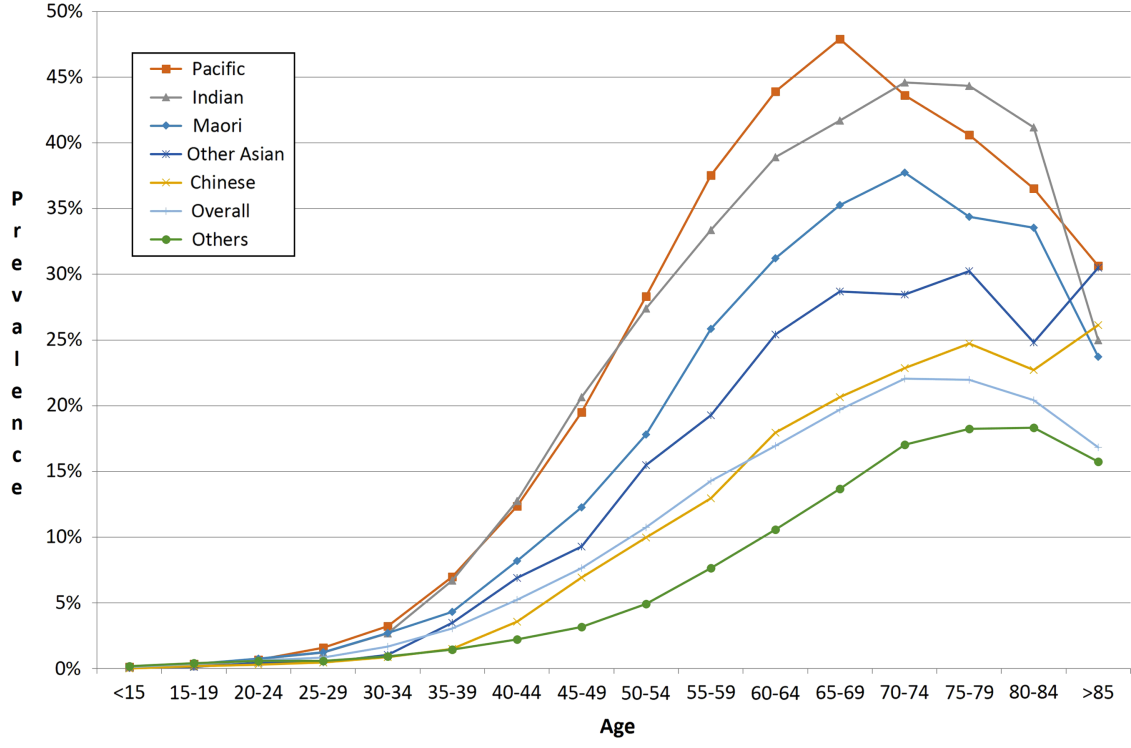

Health Board (CMDHB) in 2006/2007 was about 20\% lower in relative terms (a difference of $>5000$ people) than in the current study. ${ }^{17}$ The key methodological difference between the studies was the availability of blood test results in the current study, whereas the previous study relied on an algorithm based on hospitalisations, drug treatment and the number of HbAlc tests (without the test results being available) to estimate diabetes prevalence. Demographic changes; improvement in screening; differences in definitions of diabetes and dysglycaemia and a real increase in the underlying diabetes prevalence since $2006 / 2007$ are likely to explain the difference in results between the studies.

The HSU population (denominator) was constructed from national routinely collected administrative data; it defined the population at risk and effectively adjusted for migration and deaths. The use of current $\mathrm{PHO}$ enrolment and/or evidence of health service contact are pragmatic proxies to indicate that the HSU population was residing in the Auckland metropolitan area within the defined period of the study. The novelty and strength of this study was that the test coverage and the dysglycaemic status of each individual in the HSU population in 2010 were determined by the laboratory results in a consistent manner through individual person record linkage using a unique identifier, the encrypted NHI.

The use of the HSU population as the denominator on which to base future population registers for many long-term conditions has many technical and practical
Figure 2 Age specific prevalence of dysglycaemia in the Auckland metropolitan region in 2010 by ethnicity (females).

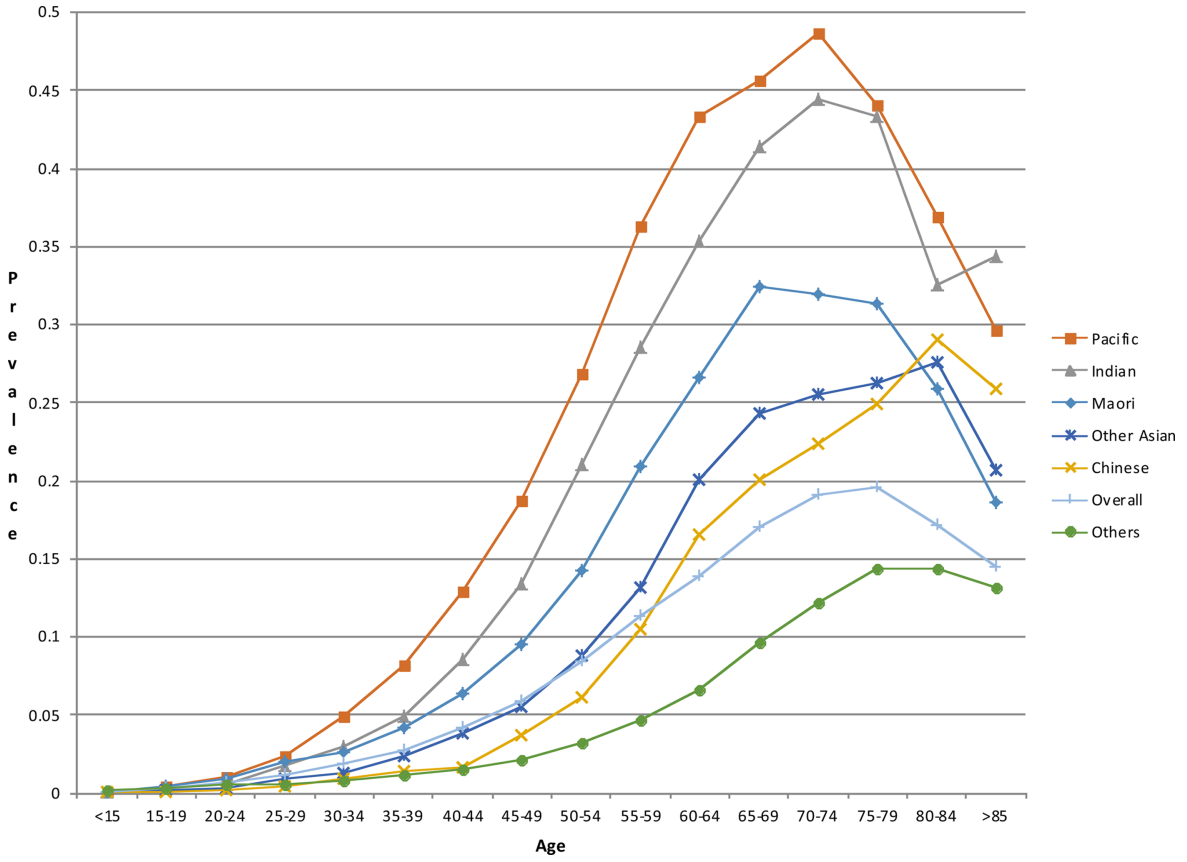




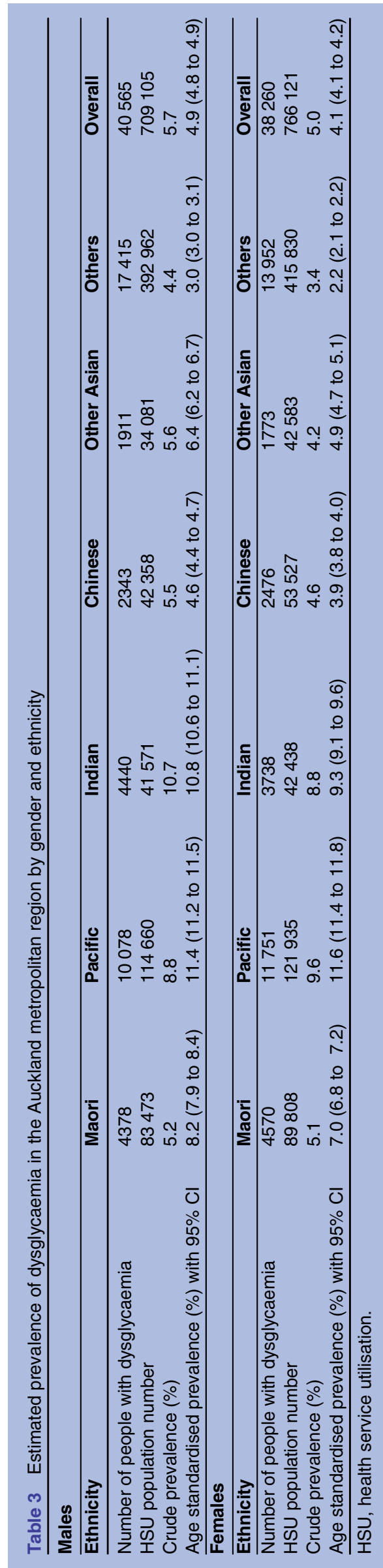

advantages in policy making and quality improvement. The HSU population ( $\mathrm{n}=1475347)$ was very similar to the estimated population of the three Auckland metropolitan District Health Boards from Statistics New Zealand in June $2010 \quad(\mathrm{n}=1477600) .{ }^{14}$ In practical terms, virtually everyone with significant disease who resides in the Auckland metropolitan area is likely to be currently enrolled in a primary care practice and/or have had a contact with publicly funded health services during the year. The way the HSU population was defined means that if identifiable data were used as part of a population register, it can potentially identify any potential performance gaps that a healthcare provider can address at the individual level. Eligible patients could be readily recalled based on the latest contact details from primary care enrolment or from the last health service contact. This is particularly important in a context where the actual care that patients received might be suboptimal. ${ }^{18}$ For example, a systematic recall system can theoretically be set up for those people who are yet to be screened using the identical record linkage carried out by this study. As pharmaceutical dispensing data can be linked by NHI in New Zealand, a similar systematic system could also be implemented to monitor the care provision for people who are at high risk of complications. For example, it would be possible to recall those with diabetes and microalbuminuria who were not dispensed an ACE inhibitor or angiotensin II receptor antagonist, or people with poorly controlled diabetes who may need further clinical review or selfmanagement support. Many chronic care models such as Wagner's emphasised the value of clinical information systems and the role of a population registry to facilitate the provision of systematic proactive care to patients with long-term conditions. ${ }^{19}$ Indeed, an integrated electronic health record system that contains laboratory results, pharmaceutical use and utilisation of services has recently been highlighted as critical components to measure the quality of care provided. ${ }^{20}$

Other advantages of the HSU population used in this study include the elimination of numerator-denominator biases highlighted in previous reports, because all the demographic variables between the numerator and denominator were recorded in a consistent way. ${ }^{21} 22$ Furthermore, the participation of all the laboratories serving the area in the study, meaning virtually $100 \%$ of the laboratory tests performed in the Auckland metropolitan area, was included. The long-standing use of the data repository, and its incorporation in day-to-day general practice and secondary care, also contributes to the completeness and robustness of the data stored.

This study addressed many of the limitations of common sources of data that are used to estimate known diabetes prevalence-these are summarised in table $4 .{ }^{1} \quad 3 \quad 4 \quad 23-26$ Many traditional epidemiological studies are based on surveys that are subject to selection bias and patient-recall biases. ${ }^{1}{ }^{4}$ Self-reported diabetes prevalence estimates are often lower than estimates 
Table 4 The limitations of common sources of data used to estimate diabetes prevalence

\begin{tabular}{|c|c|}
\hline Sources of data & Limitations \\
\hline Self-report survey & Selection/sample bias, patient recall bias, limited sample size \\
\hline $\begin{array}{l}\text { Survey with one } \\
\text { laboratory test }\end{array}$ & $\begin{array}{l}\text { Selection bias; cross-sectional measure; poor repeatability with glucose tests; estimates the } \\
\text { undiagnosed diabetes based on patient recall or medical records; not necessarily unknown to } \\
\text { the entire health system }\end{array}$ \\
\hline Primary care records & $\begin{array}{l}\text { Inconsistency in primary care coding; subject to migration bias; may miss diagnosis at } \\
\text { secondary care or other healthcare providers; limited sensitivity in general }\end{array}$ \\
\hline Hospitals & $\begin{array}{l}\text { Only identifies those with diabetes who attended hospital; recent changes in ICD coding } \\
\text { standards may affect consistency. Major undercount }\end{array}$ \\
\hline $\begin{array}{l}\text { Pharmaceutical dispensing } \\
\text { data }\end{array}$ & $\begin{array}{l}\text { Diet-controlled diabetes would not be captured; adherence is not perfect in the community. } \\
\text { Medications may have other indications such as metformin in the polycystic ovarian syndrome } \\
\text { or may be used to 'prevent' diabetes }\end{array}$ \\
\hline Combination of datasets & $\begin{array}{l}\text { Depends on quality of the datasets combined. Needs a unique patient identifier for linkage to } \\
\text { avoid double counting. The definition of diagnoses may not be consistent across the datasets }\end{array}$ \\
\hline Capture-recapture & $\begin{array}{l}\text { Identifies people with diabetes not captured by the system (note-not undiagnosed diabetes). } \\
\text { Assumes list independence, and all individuals have the same probability of being captured by } \\
\text { each dataset. The estimates can be influenced by factors that are completely unrelated to } \\
\text { diabetes prevalence such as changes in ICD coding standards, or admission threshold, and } \\
\text { treatment trends. One cannot identify the individuals. }\end{array}$ \\
\hline
\end{tabular}

based on biochemical results. ${ }^{4}$ Most epidemiological surveys have relied on one single laboratory measurement; however, glucose tolerance tests have limited repeatability and glucose measurements have considerable intraindividual variations. ${ }^{23} 27$ While some registers have sourced data from primary care, the quality of input data and consistency of coding could be highly variable. $^{3} 2428$ While the UK NHS Quality and Outcomes Framework (QOF) recommends a systematic approach to diagnose diabetes, primary care providers are not required to provide a supporting description on how the diabetes diagnoses are performed, other than a record of a diabetes diagnosis for the purpose of the QOF indicator. ${ }^{29}$ Indeed, QOF openly acknowledges that there are a substantial number of people who are undiagnosed or misdiagnosed. ${ }^{29}$ The ability to keep an up-to-date record of people with 'diagnosed' diabetes would also be more challenging in places where there is a highly mobile population such as in New Zealand, certain parts of Great Britain and the USA. ${ }^{30-32}$ Furthermore, a significant number of blood test results may not be requested by the general practices that are currently responsible for the patients' care. For example, as demonstrated in this study, significant numbers of laboratory tests were carried out in hospitals.

The New Zealand NHI database has identifiable information such as name, address, date of birth and selfreported ethnicity. ${ }^{33}$ The NHI number has been used in other settings of proactive care such as immunisation in New Zealand. ${ }^{33}{ }^{34}$ The duplicated NHIs are regularly cleaned and mapped back to the Master NHI. Regular audits are performed and PHOs are required to provide their patient registries to the $\mathrm{MOH}$ every quarter. Therefore, applying the methodology used in this study to construct a population register has the potential to enable a systematic approach to medical auditing. The method identifies the population eligible but yet to be screened for diabetes within a defined period or people who might have abnormal diabetes laboratory results who would benefit from proactive follow-up as defined by this study. Data security and appropriate access and use of health data across the whole of the health system are vital components to enable a population register to succeed. The balance between patient confidentiality and the adaptable use of identifiable health data to enable proactive health services should be vigorously debated. While the rationale to develop such a population register is to improve population health and equity through systematic medical audit, appropriate safeguards should be in place to limit any unintended misuse of possible confidential health data.

Ideally, clinicians should have timely access to all the available health information for the group of patients that they are clinically responsible for. However, the capacity and capability required to analyse the health data from the whole of the health system into clinically meaningful and actionable health information to be available at the point of care are not universally available from all the healthcare providers. Therefore, a central system that can apply the methods of this study has a tremendous potential to review some of the possible quality gaps that exist in the current system.

The definition of dysglycaemia used in this study is a pragmatic one which identifies a group of people with abnormalities of glucose metabolism, who are at high risk of cardiovascular complications and need to be followed up by the healthcare system for ongoing clinical support and management. ${ }^{35-38}$ People with borderline elevated HbAlc $(>48 \mathrm{mmol} / \mathrm{mol})$ may be offered dietary advice and the $\mathrm{HbA1C}$ test may not necessarily be repeated immediately in the 'real world' as it does not change immediate management. Strictly speaking, 
these people would not yet have met the diagnostic criteria of diabetes. However, they should have follow-up tests to confirm or exclude the diagnosis of diabetes, impaired fasting glucose or impaired glucose tolerance. Moreover, the proposed method of this study can be refined further to apply the different diagnostic threshold of HbA1C according to ethnicity or to local recommendations. ${ }^{39} 40$

Another limitation of this study is the imperfect sensitivity as it was based on 'real-world' data of relatively short duration, and the way dysglycaemia is currently defined the study would not have identified people with dysglycaemia or diabetes who were lost to follow-up. However, more than $91 \%$ of the HSU population who had a diabetes-related hospitalisation in New Zealand between 1 July 2000 and 30 June 2010 also had laboratory results consistent with the diagnosis. This finding suggests that a regional laboratory repository of such duration (community test results for 4 years and hospital test results for 6.5 years) would already capture a substantial proportion of people with diabetes. Many people who had a single elevated glucose test might not be followed up (to get the second test required for diagnosis). This study would also miss people who had diabetes diagnosed by laboratory tests performed outside the Auckland metropolitan area or diagnosed before 2004 and subsequently had excellent diabetes control. However, these cohorts would be identified in subsequent iterations of the population register if their diabetes control deteriorated in the future. The study did not have information related to patients' symptoms or the ability to differentiate types 1 and 2 diabetes. Since glycaemia-related blood testing coverage varies by age, gender and ethnicity, as shown in tables 1 and 2, the differential testing coverage could contribute a degree of systematic bias to this study's estimate of dysglycaemia prevalence.

In conclusion, a regional laboratory result repository linked to administrative datasets has the potential to provide highly relevant and consistent information to inform clinical decision making in a comprehensive and timely manner as well as being an excellent epidemiological surveillance tool.

\section{Author affiliations \\ ${ }^{1}$ Population Health Team, Strategic Development, Counties Manukau District Health Board, Auckland, New Zealand \\ ${ }^{2}$ Health Partners Consulting Group, Auckland, New Zealand \\ ${ }^{3}$ Sapere Research Group, Wellington, New Zealand \\ ${ }^{4}$ Endocrinology and Diabetes Service, Counties Manukau District Health Board, Auckland, New Zealand \\ ${ }^{5}$ Auckland Diabetes Centre, Auckland District Health Board, Greenlane Clinical Centre, Auckland, New Zealand \\ ${ }^{6}$ Laboratory Services, Counties Manukau District Health Board, Auckland, New Zealand \\ ${ }^{7}$ Section of Epidemiology \& Biostatistics, School of Population Health, University of Auckland, Auckland, New Zealand}

Contributors WCC designed the study methods, applied approval for access to all the relevant data, undertook the literature search, record linkage, crosschecking and statistical analysis, and drafted up and revised the paper.
He is the guarantor. GJ designed the study methods and revised the paper. CW designed the study methods, linked the administrative data to construct the health service utilisation population, and revised the paper. BO-W, DRB and RJ designed the study methods and revised the paper. PLD provided clinical diabetes input and revised the paper. MAWL undertook the record linkage, crosschecking and statistical analysis. DP undertook the record linkage and data extraction for crosschecking.

Funding This study was conducted as a result of the work undertaken for Counties Manukau District Health Board (CMDHB), New Zealand.

Competing interests BOW had received remuneration from the New Zealand Ministry of Health, as the former National clinical director responsible for sector engagement on population health targets. BOW had received payment for lectures from Novo-Nordisk, AstraZeneca, Sanofi and MSD. WCC, GJ, BOW, DRB, MAWL, and DP were paid employees of CMDHB at the time of the study.

Ethics approval Ethical approval was obtained from The New Zealand Northern X Regional Ethics Committee (NTX/10/EXP/153) and access to TestSafe laboratory results was approved by the Auckland Regional Information Systems Group (RISG).

Provenance and peer review Not commissioned; externally peer reviewed.

Data sharing statement No additional data are available.

Open Access This is an Open Access article distributed in accordance with the Creative Commons Attribution Non Commercial (CC BY-NC 3.0) license, which permits others to distribute, remix, adapt, build upon this work noncommercially, and license their derivative works on different terms, provided the original work is properly cited and the use is non-commercial. See: http:// creativecommons.org/licenses/by-nc/3.0/

\section{REFERENCES}

1. Danaei G, Finucane MM, Lu Y, et al. National, regional, and global trends in fasting plasma glucose and diabetes prevalence since 1980: systematic analysis of health examination surveys and epidemiological studies with 370 country-years and 2.7 million participants. Lancet 2011;378:31-40.

2. Tricco AC, Ivers NM, Grimshaw JM, et al. Effectiveness of quality improvement strategies on the management of diabetes: a systematic review and meta-analysis. Lancet 2012;379:2252-61.

3. NHS diabetes. Coding, classification and diagnosis of diabetes. A review of the coding, classification and diagnosis of diabetes in primary care in England with recommendations for improvement. Newcastle: NHS Diabetes, 2011.

4. Okura Y, Urban LH, Mahoney DW, et al. Agreement between self-report questionnaires and medical record data was substantial for diabetes, hypertension, myocardial infarction and stroke but not for heart failure. J Clin Epidemiol 2004;57:1096-103.

5. Morgan $\mathrm{CL}$, Currie CJ, Stott NCH, et al. Estimating the prevalence of diagnosed diabetes in a health district of Wales: the importance of using primary and secondary care sources of ascertainment with adjustment for death and migration. Diabet Med 2000;17:141-45

6. Wilson SE, Lipscombe LL, Rosella LC, et al. Trends in laboratory testing for diabetes in Ontario, Canada 1995-2005: a population-based study. BMC Health Serv Res 2009;9:41.

7. Ministry of Health. National Health Index data dictionary version 5.3. Wellington: Ministry of Health, 2009.

8. Ministry of Health. National Health Index. Secondary National Health Index 2014. http://www.health.govt.nz/our-work/health-identity/ national-health-index/national-health-index-overview

9. Ministry of Health. Establishment service specifications for essential primary health care services provided by primary health organisations. Wellington: Ministry of Health, 2002.

10. American Diabetes Association. Diagnosis and classification of diabetes mellitus. Diabetes Care 2010;33(Suppl 1):S62-9.

11. World Health Organization. Use of glycated haemoglobin (HbA1c) in the diagnosis of diabetes mellitus. Abbreviated report of a WHO Consultation. Geneva: World Health Organization, 2011.

12. Ministry of Health. Ethnicity data protocols for the health and disability Sector. Wellington: Ministry of Health, 2004.

13. Ahmad OB, Boschi-Pinto C, Lopez AD, et al. Age standardization of rates: a new WHO standard GPE discussion paper Series: No. 31. Geneva: World Health Organization, 2000.

14. Statistics New Zealand. Population projections prepared for Ministry of Health. 2011 edn. Wellington: Statistics New Zealand, 2011. 
15. New Zealand Guidelines Group. New Zealand Cardiovascular Guidelines Handbook: a summary resource for primary care practitioners. 2nd edn. Wellington: New Zealand Guidelines Group, 2009

16. Ramachandran A, Ma RC, Snehalatha C. Diabetes in Asia. Lancet 2010;375:408-18.

17. Smith J, Jackson G, Orr-Walker B, et al. A population-based approach to the estimation of diabetes prevalence and health resource utilisation. N Z Med J 2010;123:62-73.

18. Saaddine JB, Cadwell B, Gregg EW, et al. Improvements in diabetes processes of care and intermediate outcomes: United States, 1988-2002. Ann Intern Med 2006;144:465-74.

19. Bodenheimer T, Wagner EH, Grumbach K. Improving primary care for patients with chronic illness. JAMA 2002;288:1775-9.

20. O'Connor PJ, Bodkin NL, Fradkin J, et al. Diabetes performance measures: current status and future directions. Diabetes Care 2011;34:1651-9.

21. Blakely T, Robson B, Atkinson J, et al. Unlocking the numerator-denominator bias. I: Adjustments ratios by ethnicity for 1991-94 mortality data. The New Zealand Census-Mortality Study. N Z Med J 2002;115:39-43.

22. Chan WC, Wright C, Riddell T, et al. Ethnic and socioeconomic disparities in the prevalence of cardiovascular disease in New Zealand. N Z Med J 2008;121:1285.

23. World Health Organization. Definition and diagnosis of diabetes mellitus and intermediate hyperglycemia: report of a WHO/IDF consultation. Geneva: World Health Organization, 2006.

24. Gray J, Orr D, Majeed A. Use of Read codes in diabetes management in a south London primary care group: implications for establishing disease registers. BMJ 2003;326:1130.

25. Harvey JN, Craney L, Kelly D. Estimation of the prevalence of diagnosed diabetes from primary care and secondary care source data: comparison of record linkage with capture-recapture analysis. $J$ Epidemiol Community Health 2002;56:18-23.

26. Anwar H, Fischbacher CM, Leese GP, et al. Assessment of the under-reporting of diabetes in hospital admission data: a study from the Scottish Diabetes Research Network Epidemiology Group. Diabet Med 2011;28:1514-19.

27. Mooy J, Grootenhuis $\mathrm{P}$, de Vries $\mathrm{H}$, et al. Intra-individual variation of glucose, specific insulin and proinsulin concentrations measured by two oral glucose tolerance tests in a general Caucasian population: the Hoorn Study. Diabetologia 1996;39:298-305.
28. McKnight JA, Morris AD, Cline D, et al. Implementing a national quality assurance system for diabetes care: the Scottish Diabetes Survey 2001-2006. Diabet Med 2008;25:743-6.

29. NHS Employers, British Medical Association. Quality and outcomes framework for 2012/13. Guidance for PCOs and practices. London: NHS Employers, 2012.

30. Statistics New Zealand. QuickStats about population mobility Wellington: Statistics New Zealand, 2007.

31. Dennett A, Stillwell J. Population turnover and churn: enhancing understanding of internal migration in Britain through measures of stability. Popul Trends 2008(134):24-41.

32. Bogue DJ. Basics of contemporary U.S. internal mobility and immigration. In: Bogue DJ, Liegel G, Kozloski M. eds. Immigration, internal migration, and local mobility in the US. Northampton, MA, USA: Edward Elgar, 2009:1-30.

33. Ministry of Health. National Health Index questions and answers. Secondary National Health Index questions and answers. http:// www.health.govt.nz/our-work/health-identity/national-health-index/ nhi-information-health-consumers/national-health-index-questionsand-answers

34. Ministry of Health. National Immunisation Register. Secondary National Immunisation Register, 2014. http://www.health.govt.nz/ our-work/preventative-health-wellness/immunisation/nationalimmunisation-register

35. Jackson R, Lawes CMM, Bennett DA, et al. Treatment with drugs to lower blood pressure and blood cholesterol based on an individual's absolute cardiovascular risk. Lancet 2005;365:434-1.

36. Selvin E, Steffes MW, Zhu H, et al. Glycated hemoglobin, diabetes, and cardiovascular risk in nondiabetic adults. $N$ Engl J Med 2010;362:800-11.

37. Cheng YJ, Gregg EW, Geiss LS, et al. Association of A1C and fasting plasma glucose levels with diabetic retinopathy prevalence in the U.S. Popul Diab Care 2009;32:2027-32.

38. Tapp RJ, Tikellis G, Wong TY, et al. Longitudinal association of glucose metabolism with retinopathy. Diabetes Care 2008;31:1349-54.

39. Bonora $\mathrm{E}$, Tuomilehto J. The pros and cons of diagnosing diabetes with A1C. Diabetes Care 2011;34(Suppl 2):S184-90.

40. New Zealand Society for the Study of Diabetes. NZSSD position statement on the diagnosis of and screening for type 2 Diabetes. Dunedin: New Zealand Society for the Study of Diabetes, 2011. 